\title{
0 estudo da cultura organizacional: as dificuldades estão no objeto ou nas formas de defini- lo?
}

\author{
${ }^{*}$ Carmen Pires Migueles
}

\begin{abstract}
Resumo
Este artigo trata das dificuldades teóricas e epistemológicas do estudo da cultura organizacional. 0 texto parte da idéia de que maiores progressos não foram feitos no entendimento de como uma cultura organizacional se desenvolve e muda, devido à confusão entre objeto e métodos de estudo da antropologia e da sociologia, por um lado, e da psicologia, por outro. Isso tem causado uma constante dificuldade na definição do objeto de estudo e na produção de conhecimentos válidos sobre o tema. Segue-se, então, uma discussão sobre o uso crescente de pesquisas com método fenomenológico em administração e os seus riscos, como excesso de subjetivismo do pesquisador, indefinição quanto ao objeto e impossibilidade de validação de resultados. É abordada a contribuição dos clássicos da sociologia na construção do saber sociológico e na separação desse saber dos que são próprios da psicologia, para a partir daí, ter-se uma perspectiva de olhar sobre a cultura. Propõem-se, então, a perspectiva antropológica como uma alternativa promissora, baseada no método etnográfico de pesquisa e tratamento semiótico dos dados, como aquela capaz de produzir conhecimentos válidos, do ponto de vista da antropologia, e aplicáveis na gestão.
\end{abstract}

Palavras-chave: cultura organizacional, etnografia, semiótica

\begin{abstract}
In this article, the author discusses the theorethical and methodological difficulties that surrounds the study of organizational culture. It is argued that a more substantial progress has not been made in this field due to an inadequate separation of the objets and methods of study of anthropology and sociology, on one side, and psychology, on the other. This confusion of spheres has been causing a persistent difficulty on the definition of the object of analysis and consequently on the production of valid research results.
\end{abstract}

Keywords: Organizational culture, ethnography, semiotics

\section{Introdução}

Os estudos sobre cultura vêm ganhando espaço nos estudos organizacionais já há pelos menos 20 anos. Ao mesmo tempo, amplia-se a utilização dos métodos qualitativos em pesquisa, para dar conta das peculiaridades desse objeto e de outros similares que, por sua natureza, são mais bem compreendidos por esse tipo de procedimento. Mas o progresso observado na compreensão do fenômeno tem sido menor do que o que se poderia obter com o esforço despendido nessa empreitada. A reflexão sobre as possíveis causas desse modesto avanço nos conduziu, num primeiro momento, ao cerne de questões epistemológicas sobre a natureza do objeto de estudo e as formas adequadas de conhecê-lo. Estaria a dificuldade na própria natureza do objeto? A resposta é não. A dificuldade mais claramente percebida nos trabalhos sobre cultura organizacional está, antes, na inadequação da importação de teorias e metodologias próprias das ciências humanas e sociais para a compreensão do fenômeno organizacional. Freqüentemente, isso tem feito com que as pesquisas qualitativas careçam do rigor necessário a um maior entendimento sobre o tema.

Portanto, o objeto de discussão deste artigo é a maior ou menor inadequação de abordagens teóricas e metodológicas e as consequiências que isso pode ter para o emprego de métodos qualitativos em estudos organizacionais, mais especificamente para o estudo da cultura. Ainda que baseado em observações nãosistemáticas, o artigo também pretende tratar da tendência - já bastante consolidada entre estudiosos desses

*Professora Titular da ESPM/RJ. Dra. em Sociologia das Organizações e Mestre em Antropologia do Consumo - Universidade Sophia, no Japão. E-mail: cmigueles@ espm.br. 
fenômenos mais subjetivos nas organizações - de se recorrer, para os estudos qualitativos, à chamada "abordagem fenomenológica", que apesar de todos os seus méritos no campo da filosofia, apresenta, dependendo da vertente, dificuldades consideráveis quanto ao seu emprego como método científico. Muitos desses trabalhos justificam o emprego do "método fenomenológico" como alternativa ao positivismo. Contudo, não há uma alternativa, mas várias. E essas alternativas são tão mais pertinentes quanto mais validade tiverem, o que significa evitar, tanto quanto possível, o subjetivismo.

Reconhecer que a objetividade é impossível não significa ceder acriticamente ao subjetivismo. Por outro lado, o esforço para evitar o subjetivismo não é e nem pode ser considerado como sinônimo de positivismo (BOURDIEU, 1999), sob o risco de declararmos impossíveis as ciências humanas e sociais. Como muito apropriadamente afirma Geertz (1989), reconhecer a impossibilidade da objetividade não significa ceder à intuição e à alquimia, mas desenvolver métodos interpretativos capazes de nos aproximar da realidade.

\section{Sobre as dificuldades epistemológicas deste estudo}

O indicador mais claro das dificuldades teóricas e epistemológicas sobre o estudo de cultura está no fato de que muitos trabalhos sobre o tema apontam para o reconhecimento da dificuldade de abordá-lo como resultado da forma como "cultura" é conceituada. O termo cultura é apresentado como um imenso "guarda-chuva" sob o qual são abrigados os mais variados fenômenos. Esse é um problema bem abordado por Geertz (1989), mas ainda não trabalhado de forma adequada para o universo empresarial.

Se considerarmos uma idéia mais concreta - por exemplo, uma favela -, a importância de pensar sobre a utilidade, e não sobre a "verdade" de um conceito sobre o objeto, fica mais clara. Um arquiteto, provavelmente, conceituará uma favela como um "agrupamento de casas populares sem planejamento urbanístico". Um geólogo, como um "grupo de habitações construídas sobre terreno instável". Um sociólogo empregará a idéia de exclusão, conceituando favela como um "conjunto de habitações de grupo socioeconomicamente excluído"; enquanto um espírita talvez a definisse como um "grupo de pessoas que veio ao mundo para pagar um carma" etc.

Há tantos conceitos quanto usos necessários para eles, e nenhum deles jamais será o conceito "certo". em termos absolutos. O conceito, como esses exemplos indicam, delimita o recorte epistemológico dentro do qual um determinado sujeito irá trabalhar, e muitas vezes inclui, em si, um juízo de valor que orienta a ação. Portanto, o conceito arquitetônico que fala da falta de planejamento urbanístico já indica o objetivo do arquiteto ao intervir na realidade. O mesmo sendo verdade para o geólogo (que quer estabilizar o solo), ou para o sociólogo, que acredita na necessidade de inclusão social. Dessa forma, quando pensarmos em um conceito de cultura, antes de investigarmos o que "cultura realmente é", precisamos perguntar, primeiro, o que queremos fazer com o nosso estudo.

Isso é verdade para qualquer ciência, social, humana ou natural. Um engenheiro que esteja desenhando um automóvel não está preocupado com a física, no geral, nem com sua essência, mas com as ferramentas que, dentro da física, pode servir para projetar seu automóvel. Ele bem sabe que se usar a ótica em vez da aerodinâmica terá problemas para atingir os resultados planejados. Assim, ele não usa a física, mas ferramentas e teorias da física para resolver problemas concretos; por uma lógica que é instrumental em essência, pois essa é a natureza do conhecimento científico aplicado: conhecer de forma válida os fenômenos do mundo, para aumentar a potência da ação humana sobre estes.

Por isso, quando falamos de cultura, o problema fundamental não é só reescrever o conceito, mas decidir sobre qual é, afinal, o nosso objeto de estudo e qual é a sua relevância para o entendimento do fenômeno organizacional. Existem inúmeras possibilidades de aplicação, para esse estudo, de conhecimentos acumulados da antropologia, da psicologia e da sociologia. Todos ligados entre si, em uma intrincada rede interdisciplinar, com pontes epistemológicas ainda por serem construídas. Mas para progredirmos aqui, assim como no exemplo anterior, também é importante compreender o que é um conceito científico e quais são as suas limitações, para que os avanços sejam consistentes e a aplicação esteja clara. 
Entre as ciências com foco no indivíduo e aquelas com foco sociológico, há uma enorme distância conceitual que ainda não conseguimos ultrapassar; pelo que são, no momento, dificuldades epistemológicas para as quais não temos respostas, e que dificulta, sobremaneira, a interdisciplinaridade entre antropologia e sociologia, por um lado, e psicologia por outro. Isso não é uma peculiaridade apenas das ciências do homem. Se o engenheiro que está projetando o carro olhar para o universo das suas matérias-primas pelo ponto de vista do "indivíduo", do subatômico ou do átomo, não conseguirá chegar a conclusões pertinentes e relevantes sobre a aerodinâmica no projeto do automóvel. É inegável que o átomo é parte da realidade do aço, mas também na física se estão a construir as bases teóricas e metodológicas que permitam chegar a conclusões diretamente aplicáveis da escala subatômica para a outra, da física newtoniana. Portanto, o conceito deve referir-se, também, a definições quanto ao objeto, às teorias e às formas de estudá-lo.

O mesmo ocorre entre a antropologia e a psicologia aplicadas ao estudo da cultura organizacional. A antropologia é uma ciência social, enquanto a psicologia tem foco no indivíduo - embora, muitas vezes, busque compreender o comportamento social do mesmo. O risco - para quem toma emprestado, de forma desavisada, as teorias e os métodos dessas ciências - já começa aqui. Ambas estudam o comportamento humano, mas por recortes epistemológicos muito distintos. Sem dúvida que ambas estão intimamente relacionadas, mas não nos movemos facilmente de um universo para o outro sem nos perdermos.

Segundo Eliot (1988), o termo cultura tem associações diferentes, conforme tenhamos em mente o desenvolvimento de um indivíduo, de um grupo ou classe, ou de toda uma sociedade. A cultura do indivíduo depende da do grupo; e a do grupo, da sociedade. Por outro lado, a cultura da sociedade não determina a do grupo, nem esta a dos indivíduos, que processam as informações que recebem através da linguagem, dos rituais, da cultura material, de forma idiossincrática. Embora mantenha as tendências gerais da sua sociedade nas formas de ver o mundo e atuar nele, o indivíduo tem um espaço próprio de ação, por ser dotado de consciência e razão, e, portanto, capaz de refletir e atuar sobre sua realidade e sobre si mesmo.

Bourdieu (1977), Giddens (1979 e 1995) e outros cientistas sociais vêm trabalhando com a difícil interface entre lógicas macroscópicas, sociológicas ou antropológicas e a questão da ação do indivíduo; que, embora formado dentro dessas macrológicas, é inegavelmente um ser que age de forma razoavelmente livre. Bourdieu demonstra, excepcionalmente bem, os riscos de se utilizar, para a compreensão de uma sociedade, as abordagens fenomenológicas que tão bem se aplicam ao universo de algumas vertentes interpretativas da psicologia e da psicanálise. Não se pode generalizar a partir da fenomenologia (JAPIASSU, 1992; RICHARDSON, 1999). Teorias e métodos que permitam fazê-lo ainda estão por ser pensados.

Na verdade, quando falamos em fenomenologia, precisamos ser mais precisos: o que é fenomenologia, ou qual é a fenomenologia a que estamos nos referindo? Sim, porque a fenomenologia de Husserl é fundamentalmente distinta da de Charles Sanders Peirce, que por sua vez é diferente da proposta por Max Weber, que é distinta da fenomenologia subjacente ao estruturalismo de Karl Marx, dentre outros. Em termos de ciências humanas e sociais, a fenomenologia de Max Weber produz evidências empíricas válidas, pesquisáveis por métodos qualitativos; o que, por razões distintas, não ocorre com a de Marx e a de Husserl. A de Marx porque as noções de ideologia e alienação pressupõem que o ser humano tem uma falsa consciência da sua existência e, dessa forma, sua visão de mundo é distorcida, cabendo ao filósofo ou sociólogo desvendar a realidade por trás dessa falsa percepção, onde a verdade sobre a realidade vivida e percebida não está no sujeito ou no discurso que o sujeito faz sobre si e sua realidade, mas na estrutura social que molda a sua percepção. Isso elimina o sujeito da história e é uma "antifenomenologia", em termos de Husserl, onde a realidade é a realidade percebida pelo sujeito, na interação entre a sua consciência e os objetos da realidade exterior.

A fenomenologia de Marx - baseada na famosa inversão sobre a de Hegel - nos remete a questões ontológicas que não conseguem ser resolvidas no domínio da ciência; ${ }^{1}$ e a de Husserl, a um universo de percepção para o

\footnotetext{
${ }^{1}$ A forma como Marx afirma a alienação dos sujeitos no estudo da sociedade capitalista - especialmente, a forma como trata o consumo humano através do conceito de fetichismo das comodidades - dificultou aos cientistas sociais que usam sua teoria compreender de forma mais adequada o papel da cultura material na constituição das formas de sociabilidade contemporâneas. É um bom exemplo de como uma teoria ou uma perspectiva epistemológica afeta o desenvolvimento dos saberes em uma determinada área de conhecimento. Sobre interpretações alternativas: APPADURAI, 1986; BARTHES, 1984; CAMPBELL, 1987; CLAMMER, 1997; LIPOVETSKY, 1987; SAHLINS, 1976; SLATER, 1997; SLATER e TONKISS, 2001.
} 
qual a ciência não conseguiu produzir métodos de observação ou de produção de evidências válidos. Isso não invalida, de forma alguma, o valor da contribuição de ambos os autores para a ampliação do universo do pensamento humano. Entretanto, o uso que se pretende dar à fenomenologia de Husserl no campo da administração apresenta ainda outras dificuldades, que nos remetem a discussões sobre a definição do objeto de estudo e às formas de acessá-lo. Estudar a fenomenologia da percepção humana por uma perspectiva filosófica - em que é válido especular sobre a verdade dos estados psíquicos tais como percebidos pelo sujeito - é uma coisa, mas estudar esses mesmos estados numa perspectiva científica é outra. Há pouquíssimos pontos de interação estruturados, e muito menos de consenso, entre a antropologia, a sociologia, a lingüística, a psicologia e a psicanálise.

Existe uma questão sobre a qual a maioria dos pesquisadores dessas áreas tendem a concordar: o ser humano é opaco para si mesmo. Não conhece as forças culturais, lingüísticas, estruturais ou funcionais que atuam sobre sua percepção e ação no mundo, nem as formas como seu universo subjetivo distorce ou direciona a sua percepção dos fenômenos externos. A medicina moderna acrescenta ainda outras dificuldades ao estudo da percepção dos estados psíquicos, quando comprova o impacto dos hormônios e das combinações bioquímicas sobre o nosso humor e percepção. Há ainda um outro elemento complicador do estudo do entendimento e da percepção humanos: as teorias do conhecimento apontam para o fato de que a linguagem e os signos que as compõem são estruturantes da consciência, o que torna bastante complexa a questão do estudo das estruturas ou dos processos subjetivos dos sujeitos em qualquer esforço científico (ECO, 1997). É muito difícil saber, por exemplo, através da análise do discurso de um sujeito qualquer, se as estruturas últimas ou a essência da percepção propostas por Husserl estão sendo expressos, se essa expressão é uma manifestação da consciência em sua interação com o mundo real e social, se são fatos da percepção individual moldados por processos bioquímicos ou sociológicos conjunturais, se são elementos apriorísticos da consciência, ou se são fenômenos lingüísticos que na sua interação com os mecanismos cerebrais se transformam em categorias gerais, em relação às quais outros fenômenos secundários de percepção se constituem (CHIERCHIA, 2003). Não é à toa que Husserl chama a atenção para o fato de não estar pretendendo fundar uma nova ciência, mas explorar a possibilidade de se expandir o pensamento sobre essas questões; e evitar, propositalmente, cair no domínio da psicologia. Isto não quer dizer, naturalmente, que a fenomenologia não possa ou não esteja sendo usada no desenvolvimento da psicologia. A psicologia existencialista de Medard Boss, por exemplo, funda-se sobre a fenomenologia de Heidegger, em sua corrente denominada de analítica do Dasein, mas mais como inspiração filosófica, uma vez que não cabe ao saber científico, por limitações até o momento irremovíveis, lidar com questões ontológicas. Outros desenvolvimentos - como os da Gestalt terapia, fundada por Frederic Perls trabalham a consciência corporal e outras formas de autoconhecimento, numa vertente que dialoga com certas questões levantadas por discussões filosóficas sobre a fenomenologia. Todavia, a transposição dessas perspectivas de análise para os estudos organizacionais não pode se dar de forma direta, ou com pretensões científicas, contornando desavisadamente as dificuldades epistemológicas que a psicologia vem se esforçando para resolver. Portanto, se há um lugar onde os pesquisadores que utilizam métodos qualitativos não devem buscar evidências diretas para conclusões científicas, esse lugar é precisamente no discurso e nas percepções dos sujeitos sociais. Mas é precisamente isso o que muita gente tem tentado fazer, motivados pela idéia de que estão empregando o método fenomenológico ou fazendo pesquisa qualitativa para ter acesso ao universo subjetivo dos sujeitos pesquisados. Discurso é um dado cru. Não é informação científica (e nem filosófica, uma vez que o próprio Husserl trata o discurso como evidência, e não como fato). Como dado cru, é construído, para suas aplicações na ciência, através de um esforço ao mesmo tempo teórico e metodológico que pode ser qualquer coisa, menos uma empreitada simples (BRANDÃO, 2002). Dessa forma, não é uma questão que se resolva com um simples questionário, com uma tosca observação participante ou com algumas entrevistas em profundidade a serem usadas de forma direta como "evidência".

O esforço para não enveredar pela complexidade das questões (inevitáveis) do conhecimento científico - no pretenso intento de estudar "administração" e não psicologia, antropologia ou sociologia; somado ao esforço (mal direcionado, na maioria das vezes) para escapar das "abordagens positivistas", através do emprego do "método fenomenológico" - tem levado às dificuldades recorrentes na definição clara de objetos de análise em muitos estudos onde questões organizacionais encontram essa interface com as ciências humanas e sociais. No 
entanto, é precisamente o não reconhecimento das dificuldades subjacentes ao "método fenomenológico" que tem levado sucessivas levas de estudantes a se perder na falta de consistência e no excesso de subjetivismo que essas tentativas têm gerado, impedindo o desenvolvimento adequado dos estudos de cultura organizacional e levando a uma profusão de textos sobre o tema em que se fazem afirmações muito pouco claras e fundamentadas sobre cultura, sem prever a possibilidade de verificação das conclusões por outro pesquisador.

O uso de métodos qualitativos e estratégias interpretativas não pode ser sinônimo de falta de estratégias de validação dos dados, o que só é possível se o objeto está claramente recortado, a estratégia de coleta de dados está adequada ao esforço por compreendê-lo e a pesquisa está firmemente ancorada em uma perspectiva teórica que aponte para conclusões. E justamente por não poder, pelas peculiaridades do objeto, lançar mão da estatística ou outras ferramentas de validação mais claras para estabelecer causa e efeito ou presumir relação, uma atenção especial à qualidade da leitura teórica precisa ser dada - além do cuidado redobrado por apresentar, no texto, amplas evidências empíricas das conclusões a que se chegou -, para que o leitor possa julgar a pertinência da análise e a adequação dos dados. Contudo, esses cuidados vêm sendo dispensados em nome do combate ao positivismo. Porém, em ciências humanas e sociais, positivismo não é sinônimo de falta de rigor e de estratégias adequadas de validação dos dados. Nesse sentido, as críticas que os pesquisadores em ciências humanas e sociais vêm fazendo, com força razoável, ao positivismo, por mais de meio século, referemse às tentativas de se impor os métodos das ciências naturais às ciências sociais e, também, à tentativa de construir uma ciência social apresentando conclusões com validade externa em relação ao conjunto de circunstâncias em que o estudo foi feito. No entanto, reconhecer que em ciências humanas e sociais faz sentido recorrer à validade interna e que a perspectiva do pesquisador interfere no objeto - o que pressupõe esforços interpretativos do contexto e reconhecimento dos limites da análise - não significa abrir mão da questão da validade nem cair nas armadilhas do subjetivismo do pesquisador (GIDDENS e TURNER, 1999; BOURDIEU, 1999).

Para termos uma noção mais clara dos objetos estudados por métodos qualitativos em sociologia e antropologia, vale a pena recorrer a alguns dos clássicos dessas ciências. Para Durkheim, os fatos sociais (para ele, o objeto de estudo da sociologia) seriam "toda a maneira de agir ou pensar, fixa ou não, capaz de exercer sobre o indivíduo uma coerção exterior, apresentando uma existência própria, independente das manifestações individuais que possam ter" (DURKHEIM, 1991). Para Max Weber, a sociologia estuda os processos sociológicos formais e racionais, embora isso não signifique afirmar uma preponderância efetiva do racional sobre a vida, ou ainda: a sociologia estuda os processos subjetivos por uma perspectiva estritamente não psicológica (WEBER, 2000).

Por que esse cuidado em evitar o domínio da psicologia por Weber? Por que o cuidado em Durkheim ao afirmar que os fatos sociais têm existência própria, independente das manifestações individuais que possam ter? Ou ainda, se olharmos para Marx, por que recorrer à análise da estrutura social para compreender o comportamento humano em sociedade? Isso é parte de um grande esforço epistemológico para garantir a possibilidade de produção de uma ciência social, com um objeto passível de ser estudado de forma válida. Assim, vamos usar um exemplo concreto para percebermos a dificuldade de operacionalizar pesquisas que ultrapassem os limites desses objetivos específicos.

Vejamos o caso do projeto de uma linha de montagem para produção de automóveis: para os engenheiros e equipes técnicas envolvidas no projeto, trata-se apenas de um projeto tecnológico, para o qual é necessário o investimento de recursos materiais, humanos, capital e conhecimentos. Um sociólogo examinando o mesmo projeto verá, aí, um conjunto de outras questões: A percepção cultural que essa equipe tem da divisão social do trabalho na nossa sociedade, herdada da cultura greco-romana, torna possível a concepção de um conjunto de tecnologias que separa o trabalho de concepção daquele de execução, que emprega pessoas em tarefas meramente complementares às das máquinas.

Há uma visão racional-instrumental do ser humano no universo da produção, que torna possível a reprodução de certas formas bastante específicas de divisão social do trabalho e mantém a tendência de divisão social por classes na nossa sociedade. Isso torna lógicas e racionais as ações humanas, em conjunto, orquestradas para a 
concretização do projeto, e permite a concordância das inteligências sobre as formas adequadas de fazê-lo. É isso o que Weber chama de processos sociológicos formais e racionais. Considerando-se que existem determinadas formas de se ver o mundo (que são subjetivas, pois encontram existência e articulação no universo subjetivo dos sujeitos) é natural e racional que determinadas ações ocorram, e que a explicação ou a compreensão dessas ações só faça sentido em relação a essas lógicas. Portanto, as estruturas lógicas da ação estão sendo estudadas a partir do entendimento que os sujeitos têm sobre o que estão fazendo, entendimento esse que é partilhado subjetivamente, sem cair no domínio da psicologia. Weber recorre à semiótica para o estudo dessas estruturas e as legitima de várias formas, demonstrando como essas relações estão presentes em inúmeros domínios da vida moderna e como se estruturam as relações entre esses sistemas lógicos de pensamento que mapeou e o comportamento social por eles gerado.

Essa forma de divisão social do trabalho distribui desigualmente a informação e o acesso ao conhecimento, bem como não incorpora os saberes da base da pirâmide organizacional aos processos produtivos. Ela é mantida por uma estrutura que se relaciona às formas de organizar a propriedade e o acesso aos meios e instrumentos de produção (conhecimento, dentre estes). Em parte, é isso o que Marx estuda. Mesmo assim, essa forma de organização gerou ganhos fantásticos de produtividade na sociedade capitalista, e corresponde a determinado estágio de desenvolvimento das forças produtivas e às formas como entendia-se produtividade em um determinado momento histórico. Ao sociólogo ou ao antropólogo (e a divisão entre essas duas ciências não mais se justifica) cabe compreender esses processos sociológicos mais gerais, desde suas relações políticas e econômicas até as formas simbólicas de entendimento do mundo que as tornam possíveis e lhes dão sustentação. De certa forma, é o projeto de Durkheim: entender de que forma os fatos sociais produzem ou são produzidos por formas de colaboração social e produção de solidariedade que façam com que o sistema funcione melhor ou pior. Para buscar evidências empíricas sobre a relação valores versus solidariedade, Durkheim recorre ao estudo das leis - que é onde essas evidências estão materializadas para análise. Por isso, ele gasta tantas páginas falando das leis em seu famoso estudo sobre a divisão social do trabalho (DURKHEIM, 1999), um projeto que vem sendo retomado com resultados animadores por Douglas (1998).

Os vários objetos de estudo aqui configurados, referem-se, antes de mais nada, à construção do universo do sentido supra-individual (cultura, simbolismo) bem como às condicionantes objetivas das situações concretas das quais o sujeito participa, e que se estruturam como realidade externa inelutável, formadora do contexto no qual o indivíduo precisa, necessariamente, operar. É claro que, como afirma Weber (2000), "as intenções, interações e cooperações dos seres humanos interessados e orientados atuam continuamente sobre fatos e contextos na sociedade e na história, e podem influenciá-las e formá-las até certo grau geralmente indeterminável: se não fosse assim, não haveria ações. Mas, da mesma maneira, o desenvolvimento das circunstâncias e os contextos da realidade social-histórica determinam o mundo ideal e as intenções de seres humanos praticamente ativos, uma vez que estes - em virtude da experiência social - conhecem as circunstâncias e os contextos, e por eles se orientam". Isso quer dizer que sujeitos sociais alteram contextos sociológicos, mas de forma específica e sob condições específicas. Por exemplo, sujeitos que se recusem a colaborar no projeto anteriormente mencionado têm muito mais chances de serem demitidos, excluídos do grupo e da interação social que nele ocorre, do que de alterar a forma como funciona, mesmo que se neguem a fazê-lo por uma postura política, como através de uma greve. As ações dos sujeitos podem ter consequiências inesperadas - como o recrudescimento de estratégias políticas de repressão -, que não se relacionam diretamente com os objetivos ou intenções concretas de nenhum dos agentes sociais na hora em que a decisão pela ação foi tomada.

Tanto o esforço de Max Weber quanto o de Karl Marx e o de Durkheim são esforços interpretativos que buscam as causas do comportamento social em domínios que estão fora dos limites da consciência humana. Essas idéias compõem o acervo de possibilidades teóricas da sociologia, juntamente com o interacionismo simbólico, o pós-estruturalismo, a etnometodologia, dentre outras, sendo alternativas ao método positivo proposto por Augusto Comte. Embora Durkheim tivesse revelado a intenção de tornar possível que o funcionalismo viesse a ter validade externa em algum momento no futuro, o potencial interpretativo de seu método o mantém vivo e atuante na sociologia contemporânea. 
Nessas tendências mais macroscópicas - para cujo estudo não é necessário compreender o universo subjetivo de indivíduos específicos -, estão abrigadas inúmeras questões de pesquisa que precisam tomar os indivíduos como ponto de partida. E aqui entra o domínio da psicologia. Mesmo que o pesquisador esteja querendo produzir conhecimentos gerais sobre as formas como os seres humanos funcionam no trabalho, ou processam cognitivamente a cultura - e dependendo da linha de investigação, a psicologia tem muito mais possibilidades de produzir conhecimentos com validade externa do que a sociologia e a antropologia -, o objeto de pesquisa, análise e experimentação são os indivíduos. Só que os conhecimentos produzidos nesse domínio dificilmente são "transportáveis" para o outro, da sociologia. Considerando-se, por exemplo, a perspectiva de um determinado indivíduo, é possível compreender sua resistência ao poder da chefia, levando-se em conta suas idiossincrasias, ou mesmo, tendências desenvolvidas na infância quanto ao relacionamento com a figura paterna, dentre outros aspectos. Entretanto, através desse recurso, não podemos compreender o fenômeno sociológico da resistência ao poder, sem cair numa simplificação injustificável dos processos políticos que ocorrem no local de trabalho. Isto é, existe o fato psicológico de que os seres humanos se relacionam com o poder através de como processaram subjetivamente sua relação com a autoridade ao longo da vida, especialmente na infância, mas esse fato ainda está por ser relacionado à forma como a concordância das inteligências se processa sociologicamente, de modo racional, em sentido weberiano, no que diz respeito aos processos de reconhecimento e legitimação do poder e da autoridade.

A questão que vale a pena colocar é: até que ponto os engenheiros envolvidos no projeto da linha de montagem de automóveis mencionada anteriormente estão conscientes de que essas forças operam sobre suas ações? Até que ponto estão conscientes de que o seu projeto técnico tem implicações tão amplas para as formas de organização social? Até que ponto têm consciência de que há uma lógica instrumental agindo no seu projeto, ou que as formas clássicas (greco-romanas) de percepção social do trabalho orientam a sua ação? Como a ordem social é mantida em face da desigualdade na distribuição dos benefícios do trabalho (e dos prazeres e dores do trabalho também)? Como a concordância das inteligências sobre o que fazer se processa? Ou, ainda, até que ponto reconhecem na sua ação suas formas próprias de relação com o poder, e suas causas na infância? Se eles não estão conscientes desses processos, o que a expressão discursiva das suas vivências contribui para o entendimento sociológico ou psicológico desses fenômenos? Métodos qualitativos são fundamentais para estudar esse tipo de fenômeno, principalmente, porque os sujeitos não têm consciência desses fatores e não podem, portanto, responder a um questionário diretamente construído para prover essas respostas. Portanto, o discurso dos sujeitos sobre suas práticas precisa ser analisado por uma perspectiva teórica previamente definida; e entrevistas em profundidade precisam ser feitas, também, com objetivos prévios, de modo a colher material sobre os problemas ou hipóteses previamente formulados, a não ser que se esteja fazendo o levantamento preliminar de uma situação. Todavia, mesmo um levantamento preliminar precisa ser teoricamente informado. Do mesmo modo, os limites dos questionários precisam ser compreendidos. Questionários são ferramentas para coletas de dados mais adequadas para o processamento quantitativo de dados, ou seja, para quando os sujeitos têm consciência das questões perguntadas, tais como: em quem você vai votar nas próximas eleições; ou ainda, você prefere comer carne ou vegetais no almoço de domingo?

Isso não quer dizer, no entanto, que uma vez compreendido o fenômeno sociológico, não seja possível e desejável validá-lo através de questionários especialmente desenhados para esse fim. O processo de compreensão em si depende de um esforço por escolher e construir métodos qualitativos eficazes e válidos para produzir o tipo de informação necessária para que se atinjam os objetivos da pesquisa (BOURDIEU, 1984). Métodos qualitativos não precisam estar baseados, necessariamente, em análise de discurso, entrevistas em profundidade ou questionários. Às vezes, uma boa análise documental ou uma observação participante produz resultados muito melhores. Depende do que se está buscando. Essa é toda a questão: definir o que se busca e por quê. Só então é possível saber como obter e tratar a informação. 


\section{Sobre o estudo da cultura organizacional}

O proposto aqui é que se o nosso objetivo é compreender a lógica que informa os comportamentos dentro de uma organização, o nosso objeto de estudo é a gramática simbólica desse grupo. Se investigamos essa gramática a partir do indivíduo, podemos perfeitamente estar estudando a forma como ele vê ou varia em relação às médias de uso, e não essas médias. Esse conhecimento pode ser válido para o psicólogo, dependendo do seu objetivo de estudo, mas não para o antropólogo ou para o estudo de cultura. Por isso, Geertz (1989) propõe que a antropologia estude não as percepções idiossincráticas, mas os comportamentos, através do método etnográfico, tratando-os como ações simbólicas - com duas contrações: a primeira porque o comportamento é uma ação; a segunda porque é uma ação logicamente possível dentro de um determinado contexto. Isso quer dizer que trata-se de uma ação que faz "sentido" prático, eficaz, instrumental - ou seja, uma ação concreta sobre o mundo, voltada para a produção de um resultado - e que, da mesma forma, faz sentido simbolicamente, pelo que revela sobre como essa comunidade percebe o mundo e as necessidades de ação sobre ele, sobre como essa mesma comunidade se organiza internamente e de que modo esta percebe sua forma de organização, para agir. Em uma abordagem antropológica, o que estaremos tentando compreender é porque aquele comportamento é logicamente possível dentro daquele contexto. Numa abordagem psicológica, o que estaremos tentando entender é como e porque esse indivíduo age assim. Os objetos e os objetivos são distintos.

No entanto, há muita confusão entre os conceitos dessas disciplinas aplicadas às organizações. Parte da confusão,creio,resultaria de conceitos pouco precisos e de perspectivas teóricas e epistemológicas pouco claras. Proponho, então, tomarmos o conceito de Edgar Schein como ponto de partida, ${ }^{2}$ para pensarmos essa questão, uma vez que o seu conceito é o mais amplamente utilizado nos estudos sobre cultura organizacional:

"Cultura é um padrão de pressupostos básicos compartilhados que o grupo aprendeu conforme resolvia seus problemas de adaptação externa e integração interna, e que funcionou bem o suficiente para ser considerado válido e, portanto, ser ensinado aos novos membros como uma maneira correta de perceber, pensar e sentir em relação a esses problemas" (SCHEIN, 1992, p.12).

Segundo Schein, essas pressuposições básicas são constituídas por crenças inconscientes, taken-for-granted (inconscientemente aceitas como verdadeiras), percepções, pensamentos e sentimentos (fonte última dos valores e da ação). Sobre essas pressuposições básicas, emerge um conjunto de valores compartilhados (estratégias, objetivos, filosofias - justificativas compartilhadas), e, por último, os artefatos, que são as estruturas e os processos organizacionais visíveis.

Pensando sobre o conceito proposto por Schein, podemos fazer algumas perguntas úteis que talvez nos ajudem a melhor assimilar sua contribuição, e a extrair desta um objeto passível de ser teórica e metodologicamente trabalhado, de forma consistente e útil para as organizações. A primeira pergunta seria: o que são especificamente esses pressupostos básicos? Se eu não posso determinar a sua natureza, o que, exatamente, estou estudando? Por exemplo: o que são crenças inconscientes? É algo que está no inconsciente dos indivíduos? Será que os indivíduos partilham desse universo? Se partilham, como chegaram a isso e como eu posso acessá-lo? Para que partilhemos de uma cultura, devemos ter pensamentos e sentimentos comuns? Por quais métodos esse universo é "pesquisável"? Nesse ponto, a minha intuição é a de que temos um objeto que circula entre o social, o coletivo e o universo do inconsciente individual, de forma bastante fluída e inacessível. Nesse sentido, essa é uma definição de cultura operacionalizável em termos de pesquisa? A resposta é não, porque ou eu defino e fixo meu objeto de estudo ou não estou pesquisando nada em especial. Com um conceito de cultura como esse, pode-se dizer qualquer coisa, sem estar necessariamente certo ou errado, mas também sem contribuir de forma útil para o entendimento do que possa vir a ser a cultura de uma organização.

Geertz propõe a idéia de que uma cultura é, fundamentalmente (se escolhemos analisá-la por um recorte epistemológico voltado para estudar a estrutura lógica da ação), uma hierarquia estratificada de estruturas

\footnotetext{
${ }^{2}$ Segundo o conceito proposto por Schein, a decisão de partir vem da constatação que sua definição de cultura é a mais empregada nos trabalhos sobre cultura organizacional no Brasil. Ele é citado na grande maioria dos trabalhos sobre o tema, e teve uma influência marcante em quase todos os trabalhos nos quais é mencionado.
} 
significantes em termos das quais a ação humana é produzida, percebida e interpretada - ou seja, o estudo da cultura é uma busca por estruturas de significação, determinando, ao mesmo tempo, sua base social e sua importância. Assim, creio que esse seja um bom ponto de partida para desatar esse nó: cultura não é sinônimo de sentimentos, valores ou crenças partilhados, mas, antes, formas compartilhadas de perceber a realidade em termos de que esses valores e crenças individuais podem ser compreendidos. E o que são essas estruturas?

De acordo com Geertz, são a gramática simbólica de uma determinada sociedade, e que podem ser estudadas através da semiótica. A semiótica - ciência geral dos signos - é o campo do conhecimento que estuda a comunicação humana, não apenas quanto a sua capacidade de transmitir mensagens, mas de constituir-se através de meios simbólicos. Segundo Eco, é o artifício teórico e epistemológico que trata todos os elementos da cultura como fenômenos de comunicação (ECO, 1997). Por exemplo: ao observarmos uma mãe indiana que aponta uma vaca para seu filho, dizendo "Olha a vaca!" e uma mãe brasileira fazendo a mesma coisa. Verificamos no dicionário que os termos são sinônimos em português e hindi, mas apenas quanto à realidade que denotam, ou seja, o animal que muge e pasta. Entretanto, os termos não se equivalem quanto ao que conotam, ou quanto ao significado cultural de "vaca" nessas duas culturas (numa, um animal empregado na produção de alimentos; na outra, um animal sagrado). Vaca só tem esses significados nessas duas culturas porque é parte de uma teia de significados na qual faz sentido que seja assim. Esses significados compõem uma gramática, que é uma estrutura de percepção do mundo, ou várias estruturas, muitas vezes, sobrepostas, como propõe Eco (1997 e 2000). Compreendendo essas lógicas culturais, podemos entender porque um indiano passando fome não come uma vaca - e afirmar que ele provavelmente não o fará, com alto grau de acerto -, e porque o brasileiro o faz.

Examinaremos um exemplo prático, para tornar essa noção mais clara. Vamos comparar as concepções sobre o trabalho no Brasil e no Japão.

Tanto na cultura japonesa quanto na cultura brasileira, o trabalho intelectual, de concepção, tende a ser percebido como superior ao trabalho manual. Em sociedade, as pessoas são hierarquizadas de várias formas, a partir de como se atribui valor ao tipo de atividade que executam. Mas entre Brasil e Japão há diferenças na percepção dessa superioridade. Por exemplo: um engenheiro recém-formado, quando consegue um emprego numa empresa brasileira, tende a assumir, imediatamente, uma posição hierarquicamente superior a qualquer operário da casa. Isso para nós é absolutamente normal e plenamente justificável, pois de modo geral não valorizamos a experiência prática do fazer como uma forma de saber, ou a percebemos como tendo um valor bastante periférico em relação a outros saberes. Para nós, o saber operário não é sinônimo de uma certa maestria prática, mas de falta de qualificação. O conhecimento tácito, para nós, não tem valor claro. O salário desse engenheiro, certamente, será maior do que o do operário com o maior tempo de casa, e o engenheiro não se sentirá nem um pouco constrangido em dar ordens ao operário, sem consultá-lo sobre o assunto.

Na empresa japonesa, em que saber fazer é reconhecido como um saber, e na qual o saber com o corpo (taiken), ter a experiência prática, é visto como um complemento absolutamente indispensável ao saber teórico, essa relação é diferente. $\mathrm{O}$ engenheiro recém-formado vai trabalhar sob supervisão do operário experiente no chãode-fábrica para conhecer, na prática, o processo produtivo, vendo seus problemas e dificuldades. Seu salário inicial é inferior ao do operário que, inclusive, é quem lhe dá orientações sobre como proceder. Além disso, no Japão, demonstrar - ao longo do tempo, pelo empenho, esforço e dedicação - um compromisso firme e moral com o sucesso da organização é extremamente valorizado e reconhecido, por intermédio de uma série de estratégias sutis de reconhecimento. $\mathrm{O}$ engenheiro, para adquirir um status completo de membro, terá que construir - também ao longo do tempo - seu espaço no grupo. Um operário dedicado numa empresa brasileira não é visto como tendo o mesmo valor que um operário dedicado numa empresa japonesa. $O$ poder do laço de "pertencimento" estabelecido por essa via é bastante desigual. A empresa brasileira, de modo geral, não se percebe como minimamente responsável pelo bem-estar e pelo futuro desse operário (BARBOSA, 1999), e nem reconhece a importância do seu empenho para o sucesso da organização. Em épocas de crise, demite-se o operário com bastante facilidade e acredita-se que é possível substituí-lo por outro, se a necessidade futura da produção assim demandar. O operário tem pouquíssimo poder para influenciar o seu próprio destino dentro da 
organização, e de modo geral, não consegue construir uma reputação sólida o suficiente para determinar a sua permanência.

Se pensamos em termos de hierarquia estratificada de estruturas significantes, percebemos que, no Brasil, o saber teórico tem uma posição privilegiada como fator hierarquizante de pessoas, enquanto que no Japão o valor dessa forma de saber precisa, para atribuir status, estar vinculada a todo um conjunto de atitudes cultivadas e comprovadas com o tempo.

Essas formas de ver o trabalho e de hierarquizar as pessoas pelo tipo de trabalho que fazem não determinam a maneira como os indivíduos vão construir o seu papel na organização. Na empresa brasileira, é possível existir um engenheiro que - por princípios, valores ou crenças pessoais - se relacione com o operário de uma forma democrática, enquanto que outro, na mesma empresa, o faça de forma autoritária. O fundamental, aqui, é perceber que, em ambos os casos, o que torna o seu comportamento inteligível para os outros - e uma possibilidade de ação para eles mesmos - são as formas comuns de entender a hierarquia, bem como as formas e as variações possíveis de se relacionar ou posicionar diante dela. As ações do democrata e do autoritário são igualmente possíveis e igualmente inteligíveis no contexto da empresa brasileira. Mas não seriam igualmente possíveis ou igualmente inteligíveis na empresa japonesa. A ação é uma forma de linguagem - precisa ser compreendida e fazer sentido dentro de um dado contexto. Dessa forma, o estudo da cultura é o estudo dessas estruturas semióticas e dos contextos nos quais elas se inserem. É pesquisável pelo método etnográfico e visa compreender as redes de significados que informam as ações e a interpretação das ações (MIGUELES, 2003).

Quer dizer que cultura nacional e cultura organizacional são a mesma coisa, e que estudando uma é possível entender a outra? Não. Quando se estuda uma cultura nacional, busca-se uma média de usos de caráter bastante amplo e geral, e que, como qualquer generalização, apresenta dificuldades de explicar as variações locais. A própria definição de cultura nacional é complicada, pois em que sentido podemos dizer que um executivo de uma grande empresa paulista e um agricultor da caatinga possuem uma mesma cultura? Vamos encontrar muito mais similaridades nas formas de ver o mundo de um executivo brasileiro e um executivo argentino, do que entre o executivo e seu compatriota camponês desfavorecido pela sorte. No entanto, existem algumas características gerais suficientemente difundidas e comuns para que possamos falar em médias de uso. Dessa forma, embora culturas organizacionais e nacionais não sejam sinônimas, é importante perceber que a cultura nacional é o contexto maior dentro do qual as culturas organizacionais se inserem, e que lhes dá características próprias, muitas delas, fora do escopo e das possibilidades de gestão passíveis de interferência por parte da empresa. Por melhor que se tente gerir a cultura de uma empresa, não há uma margem de variação possível que permita transformar brasileiros em japoneses e vice-versa. As pessoas não entram na empresa como páginas em branco nas quais se pode escrever livremente uma certa estratégia de gestão. ${ }^{3}$

Nesse ponto é que gostaria de adotar a idéia de que quando falamos em valores e crenças, estamos falando, de muitas maneiras, de representações individuais. Obviamente, as representações individuais não estão desligadas da questão da cultura, no sentido de que a cultura é uma pré-condição para o ser. Não é possível ser humano, ou tornar-se humano, sem a intermediação da cultura - transmitida fundamentalmente, mas não exclusivamente, pela linguagem - e sua forma própria de construir a percepção da realidade. Todavia, a cultura não é sinônimo de representação, muito menos pode ser confundida com representações individuais. Ela é uma pré-condição para a representação e sua condição de inteligibilidade. Um exemplo dado por Lívia Barbosa, em um debate acadêmico, é esclarecedor nesse sentido: eu não posso chamar de representação da hierarquização de saberes própria da nossa cultura quando um indivíduo que tem nível educacional de terceiro grau comete um crime e vai para uma cela especial, enquanto o que não tem vai padecer numa cela hiperlotada. Isso quer dizer que a cultura está de tal forma tecida nas instituições e na prática social, que tem consequiências concretas e bastante reais para as pessoas.

${ }^{3}$ Duas boas análises das tendências da cultura brasileira e seu impacto na forma de gestão podem ser encontradas em BARBOSA, 1999, e PRATES e BARROS, 1997. 
Como isso, então, se aplica ao universo da empresa? Vamos olhar mais uma vez para a empresa brasileira. Nossa visão sobre o saber operário como um "não-saber" torna o chão-de-fábrica socialmente mudo no universo da empresa. Não existem canais institucionais que permitam que o conhecimento prático do processo produtivo flua, seja acumulado ou incorporado aos processos produtivos, a não ser - de forma ainda muito tímida - nas empresas que implementaram programas de modernização da gestão ou programas de qualidade total. Isso porque, segundo Prates \& Barros (1997), a cultura brasileira tende a produzir um modelo de gestão articulado de forma sistêmica, permeado por uma lógica personalista e autoritária, que, na base, gera uma postura de espectador. Esse modelo funciona através do formalismo como estratégia de disciplinamento do corpo social, e é flexibilizado pelo jeitinho (BARBOSA, 1992) ou pelas considerações de ordem pessoal. Isto é, há tendências bastante marcantes no exercício do poder em moldes paternalistas e personalistas que premiam não o empreendedorismo, a busca de novas soluções e alternativas para o negócio, mas a pró-atividade, que no Brasil assume a característica de ser uma antecipação dos desejos da liderança. Nesse contexto, o empreendedorismo é punido, com frases do tipo - "quem esse cara (mero subordinado) pensa que é para dizer como fazer o que fazemos há anos?" De modo geral, nega-se poder de fala à base da pirâmide organizacional.

Essa tendência, quando somada ou sobreposta aos princípios da administração científica de Taylor, que ordenou durante anos a construção dos organogramas organizacionais, gera formas de autoritarismo bastante perversas e destruidoras da capacidade de transformação das empresas. O desperdício de capital humano é enorme, uma vez que não há canais de participação para a maior parte dos membros da organização; os quais, por sua vez, por fazerem parte dessa mesma cultura, não chamam para si a responsabilidade de atuar e não percebem como contribuem para a reprodução desse modelo (MIGUELES, 1999).

Tal tendência, embora bastante dominante na nossa forma de organizar as empresas, não é determinante, no sentido vulgar do termo, pois a cultura não determina comportamentos. Aliás, nada determina o comportamento das pessoas, uma vez que o ser humano é dotado de consciência e razão e, por isso, capaz do livre arbítrio. As observações práticas nos conduzem a uma constatação inegável: esse processo não ocorre com a mesma rigidez em todas as empresas. Existem, mesmo no Brasil, empresas dinâmicas e com capacidade de atuar como agentes de mudança, enquanto que outras permanecem estagnadas ou perecem. Ocorrem processos locais de "recontextualização" dessas tendências, ao nível das relações interpessoais, capazes de redirecionar a percepção da realidade (flexibilizando a hierarquia de saberes e de pessoas, por exemplo) e de gerar formas alternativas de ação, embora bastante impregnadas da lógica da cultura nacional.

É exatamente nesse ponto que tende a ocorrer confusão entre as esferas de atuação da antropologia e da psicologia. Constata-se, empiricamente, que o executivo principal pode interferir na forma como essas relações se estabelecem dentro da empresa - e ele o faz de acordo com a sua visão de mundo; ou seja, suas representações pessoais, seu entendimento da hierarquia, da ordem, do valor das várias formas de contribuição para o seu projeto de empresa etc. Isso quer dizer que esses valores e crenças pessoais, quando traduzidos em formas de atuação para o conjunto da empresa, passam a ser vistos como o eixo principal da "cultura da organização", pois são as referências fundamentais em relação às quais todos os outros comportamentos tenderão a se definir no contexto da empresa.

Assim, o que, originalmente, eram visões de mundo pessoais e particulares passam a ter um caráter institucional, na medida em que o poder e a autoridade do executivo lhe conferem "concretude". Portanto, não se trata, simplesmente, de "visões de mundo" hierarquicamente iguais às outras, mas visões de mundo que passam a ter um peso de realidade, tendo em vista que estão associadas às estratégias disciplinares decorrentes do poder ordenador da autoridade. E mais, acredito que quanto mais uma cultura legitima formas autoritárias de poder, como a cultura brasileira o faz, negando poder de fala e espaço de atuação para a base da pirâmide organizacional, mais forte é a influência da liderança (ou da chefia, como veremos adiante) na fixação dos parâmetros de ação dentro da empresa (FOUCAULT, 1972 e 1999; LUKES, 1986).

Nesse sentido é que percebo o mérito da contribuição de Schein para esse debate. Embora ele não tenha conseguido desembaralhar essas esferas no nível teórico e metodológico, expressou uma enorme sensibilidade empírica ao perceber que cultura organizacional e liderança são duas faces da mesma moeda. Mas apesar do 
mérito do seu trabalho, o livro de Schein introduz uma segunda confusão: a idéia de liderança, quase que carismática, do maneira como é trabalhada pelo autor, nos soa falsa. É que aqui temos o peso da cultura americana, e a valorização da liderança que ela promove (BARBOSA, 1999; Da MATTA, 1979), permeando o trabalho do autor de forma inconsciente. A idéia de líder, tão clara nos trabalhos de Schein, é uma construção americana (BARBOSA, 1999). Para nós, essa noção é bastante discutível. A não ser em contextos bastante específicos, empresas brasileiras não têm líderes, têm chefes. Isso nos força a olhar para as estruturas de poder de forma mais evidente. Não que líderes sejam inexistentes na empresa brasileira, pois existe todo um universo de lideranças locais e informais dos mais variados tipos, mas a aquisição do poder formal tende a roubar-lhes legitimidade aos olhos da comunidade (MIGUELES, 1999 e 2003; BARBOSA, 1999). Ao ser promovido, o líder passa a ser chefe. As posições de poder e de liderança informal e carismática no Brasil raramente coincidem. Em termos práticos, essa diferença é fundamental porque enquanto a liderança informal constrói o seu papel e status por meio do investimento de tempo e de negociações com o grupo, o chefe tende a lançar mão das prerrogativas de poder ou das regras formais para exigir conformidade. A diferença concreta é que enquanto o líder tende a gerar um certo consenso e sinergia de ação no grupo em que lidera, o chefe gera estratégias de resistência ou passividade.

A questão do poder e do saber dentro do espaço da empresa tem uma importância fundamental na organização social e, conseqüentemente, no seu resultado. Logo, entender como esses elementos se articulam em estruturas significantes (que organizam as gramáticas simbólicas) em termos das quais a ação humana é produzida, percebida e interpretada é um dos projetos mais pertinentes das pesquisas em cultura organizacional. Mas este trabalho perde o foco se tomamos, erroneamente, os valores e crenças expressos pelo topo da organização como sinônimos de cultura organizacional. Em si mesmos, esses elementos são apenas representações individuais. Do ponto de vista da sociologia, o que nos interessa, fundamentalmente, é como esses valores e crenças se articularam no curso da interação social com os desafios, problemas e dilemas que a comunidade enfrentou fixando um certo contexto de atuação (ECO, 1997). E também, é claro, como as formas expressas ou sutis de resistência a esse discurso interferiram nesse processo, pois cultura é não só uma pré-condição para a formação do consenso, mas também para a discordância e o dissenso.

Como os contextos são criados por interações sociais em fluxo, uma cultura organizacional não é algo rígido, fixo, ou dado. Elementos novos que alterem o contexto também modificam a dinâmica das interações sociais, a lógica da seletividade, levando a uma recontextualização de atos e discursos, a formas de desintegração ou reintegração e à transformação dinâmica das personalidades (CASEY, 1995; Kunda, 1992; KONDO, 1990). Não podemos nos esquecer de que a cultura não é só uma forma de perceber, mas também de atuar sobre a realidade. Mudanças de políticas administrativas, mudanças na lógica da competição no mercado, a introdução de novos modelos de gestão, especialmente quando acompanhados por mudanças no sistema de remuneração (i.e. introdução de modelos de remuneração estratégica) causam impactos, de graus e intensidades variados, sobre a "cultura" da organização. De todas as transformações recentes - ao menos, pelo que pude observar a partir dos meus estudos de caso -, a implantação da garantia de qualidade (normas ISO) foi o que mudou de forma mais profunda a cultura das empresas brasileiras, precisamente porque afetou a relação poder/saber como eixo estruturante das interações sociais. Porém, chama a atenção o sucesso da implantação desses programas também estar vinculado ao grau de compromisso das lideranças (ou chefias) com o seu sucesso e, em certa medida, do seu maior ou menor apego ao poder. Um maior apego ao poder ameaça de maneira bastante direta o sucesso desses programas. Esse apego ao poder se concretiza, de muitas maneiras, como uma estratégia para alguém se manter no papel de quem define o que é certo e o errado, bom e ruim, dentro da empresa. Quer dizer, há uma grande dificuldade de se abrir mão da prerrogativa fundamental do poder na empresa brasileira, que é a de determinar a "verdade" em relação a qual todas as outras se definem por afirmação ou negação.

Todavia, por mais que reconheçamos que uma cultura se modifica, essas mudanças, especialmente se planejadas, esbarram na forma como as subjetividades dos membros da organização foram construídas, no curso de um longo processo de socialização dentro da cultura nacional e dentro da empresa propriamente dita. Por exemplo, se observarmos como a linguagem não-verbal expressa e reproduz a hierarquia de poder, podemos perceber a intensidade da experiência emocional (sentimentos de apreensão, ansiedade etc.) que permeiam as relações desiguais. Isso fica bastante claro quando se tenta romper a hierarquia tradicional para 
que sejam aplicadas estratégias de gestão mais igualitárias e participativas. É comum ouvir daqueles em níveis hierárquicos superiores a preocupação de que a redução do poder das hierarquias formais leve ao caos dentro da empresa, mostrando como suas concepções de ordem estão permeadas por contornos autoritários. Alguns assimilam, depois de passarem por programas de treinamento e reeducação para o trabalho, a importância da horizontalização e da delegação de autoridade para criar canais institucionais que permitam agregar conhecimentos aos processos produtivos. Entretanto, na hora de treinar o chão-de-fábrica para trabalhar nesses moldes, encontramos ainda outras barreiras. Os operários, especialmente os mais antigos, que incorporaram a sua posição inferior na hierarquia numa construção subjugada da sua subjetividade, têm uma enorme dificuldade de comunicação com seus superiores hierárquicos. Há toda uma linguagem não-verbal que expressa inferioridade/humildade e o reconhecimento do "seu lugar" na ordem das coisas, e que é uma barreira à nova ordem que se quer implantar. Isso significa que a cultura não é apenas um "estado da mente", mas também do corpo (BOURDIEU, 1977), e está profundamente tecida com as formas como a nossa emoção e processos identitários se constituem. O superior hierárquico "lêe" essa postura e falta de assertividade como sinônimos de ausência de conhecimentos, e reforça seu próprio preconceito de que o chão-de-fábrica é incapaz de pensar de forma clara e de agregar valor ao processo produtivo. O descrédito na possibilidade de mudança começa, muitas vezes, pela leitura desses sinais como prova da impossibilidade prática de mudar.

Portanto, uma mudança de cultura bem planejada não depende somente de uma gestão competente dos processos organizacionais. Paralelamente, também depende de um apoio psicológico que auxilie os indivíduos a lidarem com a mudança - sem se esgotarem pelo stress e pela ansiedade ao longo do processo - e a desenvolverem ferramentas subjetivas para recontextualizarem suas ações e representações, de acordo com a nova ordem. Dependendo do tipo de apoio que precisarmos, necessitaremos recorrer aos conhecimentos de diferentes correntes da psicologia. Nesse sentido, inúmeras pesquisas se fazem necessárias em psicologia aplicada às organizações. Essas pesquisas abrangem desde a compreensão de como os indivíduos processam cognitivamente a cultura do local de trabalho até o desenvolvimento de ferramentas ou dinâmicas capazes de promover a consciência da opressão e do sofrimento subjetivo, visando a uma gestão do conhecimento mais humana e eficaz.

Uma gestão adequada da cultura ou da mudança da cultura precisa levar em conta, fundamentalmente, esses dois aspectos: o semiótico e "comunicacional" e o aspecto psicológico da resistência à mudança; obviamente, considerando que, em ambos os casos, a forma como o poder funciona dentro da organização é o determinante do êxito do processo. Isso, entretanto, não quer dizer que se possa confundir psicologia e antropologia como ferramentas de análise e interferência na realidade organizacional na qual se pretende atuar.

A perspectiva de análise antropológica parte do pressuposto de que todos os componentes da estrutura e dos processos organizacionais têm um aspecto semiótico, compondo uma gramática simbólica e comunicando algo. Pode-se analisar todas essas "mensagens" (que comunicam mesmo que essa não seja a sua intenção) para ver se estão em concordância e se dão sustentação às mudanças que se quer implementar. Como exemplo, temos o fato de que em muitas organizações o objetivo é atingir um bom grau de integração interna e um trabalho cooperativo de times, mas a remuneração é por produtividade individual, introduzindo um elemento de ruptura na colaboração dos times. Outro exemplo é o reforço à isonomia salarial, que incentiva a acomodação. Assim, o discurso "pró-times e colaboração" esbarra em elementos concretos da organização da empresa que transmitem mensagens opostas. Muitas vezes, as empresas também investem em treinamentos e programas de integração sem perceber como, de muitas formas, as subculturas se sedimentaram dentro da organização, dificultando a integração e transformando os times em feudos de poder.

Em um caso observado numa empresa petroquímica, o próprio chão-de-fábrica estava dividido em dois grupos distintos, o pessoal da unidade que produz monocloreto de vinila (MVC) e o pessoal que produz PVC (policloreto de vinila). Havia uma série de piadas do pessoal da unidade do MVC - que é um processo percebido pelos operários como mais complexo, mais tecnológico e mais perigoso -, contra o pessoal do PVC, que era produzido em bateladas, exigia mais trabalho manual e, às vezes, deixava os operários cobertos de um pó branco. O pessoal do MVC chamava o pessoal do PVC de padeiros e perguntavam ironicamente o que iriam servir para o jantar, para irritação destes últimos. Essa piada, aparentemente inocente, provocava tamanha 
irritação porque implicava uma analogia metafórica em que o pessoal do MVC via o seu próprio trabalho como mais masculino, mais tecnológico e mais difícil; portanto, hierarquicamente superior ao da unidade da PVC, que era comparado, também metaforicamente, ao trabalho feminino, de cozinha, ou do padeiro, tradicional, mais simples, menos tecnológico e menos arriscado. Essas estratégicas simbólicas de aumentar o status de um grupo em detrimento do outro permeavam uma boa parte das interações na empresa, gerando uma série de barreiras emocionais aos programas de integração. O processo de separação e hierarquização das atividades em todos os níveis era facilitado pelo código de cores dos uniformes e capacetes, que acabaram por se transformar em símbolos de status dos grupos assim hierarquizados.

Esse é o universo de atuação do antropólogo: analisar o universo simbólico, como ele se constituiu ao longo do tempo, verificando qual sua relevância em termos sociais. Nesse sentido, é possível reorganizar esse universo, de modo a gerar uma maior sinergia de mensagens, que se reforcem mutuamente. Entretanto, o antropólogo sozinho não seria capaz de levar a cabo essas mudanças, pois desestruturaria o universo simbólico daquela comunidade, sem lhe dar sustentação psicológica, no curto e médio prazo, para que ela o reconstituísse.

\section{Conclusão}

Há uma complementaridade entre os trabalhos do antropólogo, do psicólogo e do administrador, no entendimento sobre o ser humano nas organizações. Verifica-se uma imensa demanda por trabalhos de pesquisa no âmbito da antropologia e da psicologia, para que possamos compreender melhor os mecanismos de produção de cultura e mudança. A necessidade dessas pesquisas já é bastante reconhecida, mas a dificuldade própria do campo da administração - de lidar com as questões teóricas e epistemológicas necessárias ao progresso desses estudos tem se apresentado como um fator limitante.

As causas dessa tendência precisam ser reconhecidas para que as barreiras sejam superadas. O aprofundamento na pesquisa em sociologia ou psicologia aplicadas pode roubar foco dos estudos, que devem - idealmente, sendo feitos no campo administrativo - resolver problemas próprios da administração. Mas se a decisão for por não entrar nas complexidades epistemológicas dessas áreas - já que cada uma tem objetos, métodos de ação e problemas específicos, que precisam ser respeitados - que a opção seja feita de forma consciente, adaptando-se os objetivos da pesquisa aos limites concretos das possibilidades epistemológicas escolhidas. O sucesso do trabalho depende do reconhecimento das capacidades e dos limites desses dois tipos de contribuição, de modo que o trabalho tenha sustentação prática e teórica. O mapeamento das estruturas simbólicas da cultura dentro de uma organização pode ser uma boa base para o estudo das formas específicas através das quais os sujeitos processam suas percepções, o que seria objeto de estudo, por excelência, dos psicólogos que utilizam as tendências teóricas da Gestalt. Essa interdisciplinaridade seria extremamente útil para as organizações. A psicanálise pode ajudar a compreender como essa cultura pode estar gerando diversas formas de sofrimento subjetivo, num diálogo com a antropologia que Freud iniciou já em Totem e Tabu. Pode igualmente auxiliar na investigação sobre comportamento e linguagem, um esforço iniciado por Vigotski, que embora promissor, é muito pouco explorado em sua potencialidade para a compreensão da construção do universo, ao mesmo tempo simbólico e da ação, nas organizações. As possibilidades são inúmeras, mas o fundamental a se concluir, aqui, é que pouco se constrói de consistente se o esforço epistemológico for abandonado, seja em uma ciência das organizações ou em qualquer outra. 


\section{Referências bibliográficas}

APPADURAI, A. The social life of things. New York: Cambridge University Press, 1986.

BARBOSA, L. Igualdade e meritocracia. A ética do desempenho nas sociedades modernas. Rio de Janeiro: FGV, 1999.

. 0 jeitinho brasileiro. Rio de Janeiro: Campus, 1992.

BARTHES, R. The fashion system. New York: Hill \& Wang, 1984.

BOURDIEU, P. Outline of a theory of practice. Cambridge: Cambridge University Press, 1977.

. Language \& symbolic power. Cambridge: Harvard University Press, 1982.

Distinction. A social critique of the judgement of taste. Cambridge: Harvard University Press, 1984.

The logic of practice. Stanford: Stanford University Press, 1990.

.; CHAM BOREDON, J. C.; PASSERON, J . C. A profissão de sociólogo. Preliminares epistemológicas. Petrópolis: Vozes, 1999.

BRANDÃO, H. H. N. Introdução à análise do discurso. Campinas: Editora da Unicamp, 2002.

CAM PBELL, C. The romantic ethics and the spirit of modern consumerism. Oxford: Blackwell, 1987.

CASEY, C. Work, self \& society after industrialism. New York: Routledge, 1995.

CHIERCHIA, G. Semântica. Campinas: Editora da Unicamp; Londrina: Eduel, 2003.

CLAMM ER, J. Contemporary urban Japan. A sociology of consumption. Oxford: Blackwell Publishers, 1997.

DaMATTA, R. Carnavais, malandros e heróis. Para uma sociologia do dilema brasileiro. Rio de Janeiro: Zahar, 1979.

. Relativizando. Uma introdução à antropologia social. Rio de Janeiro: Rocco, 1987.

DOUGLAS, M. Como as instituições pensam. São Paulo: Edusp, 1998.

DUM ONT, L. Homo Hierarchicus. São Paulo: Edusp, 1992.

DURKHEIM, E. A divisão do trabalho social. Lisboa: Presença, 1991.

ECO, Umberto. A estrutura ausente. São Paulo: Perspectiva, 1997.

. Tratado geral de semiótica. São Paulo: Perspectiva, 2000.

ELIOT, T. S. Notas para uma definição de cultura. São Paulo: Perspectiva, 1988.

FREITAS, M. E. Cultura organizacional: identidade, sedução e carisma? Rio de Janeiro: FGV, 1999.

FOUCAULT, M. The archaeology of power. London: Tavistock Publications, 1972.

. Microfísica do poder. Rio de Janeiro: Graal, 1999.

GEERTZ, C. A interpretação das culturas. Rio de Janeiro: LTC - Livros Técnicos e Científicos, 1989.

. O saber local. Novos ensaios em antropologia interpretativa. Petrópolis: Vozes, 1997.

GIDDENS, A. Central problems in social theory. Action, structure and contradiction in social analysis. London: The Macmillan Press, 1979.

. Social theory and modern sociology. Stanford: Stanford University Press, 1987.

Política, sociologia e teoria geral. São Paulo: UNESP, 1998.

; TURNER, J. (Org.). Teoria social hoje. São Paulo: Unesp, 1999.

GUDYKUNST, W. Explicando a comunicação interpessoal e intergrupal: uma perspectiva de manejamento ansiosa/incerta. In: RECTOR, M.; NEIVA E. Comunicação na era pós-moderna. Petrópolis: Vozes, 1997.

HARRIS, R. Power and powerlessness in industry: an analysis of social relations of production. London: Tavistock Publications LTD, 1987.

JAPIASSU, H. Introdução ao pensamento epistemológico. Rio de Janeiro: Francisco Alves Editora, 1992.

KONDO, D. K. Crafting selves, power and discourse of identity in a Japanese workplace. Chicago: University of Chicago Press, 1990.

LIPOVETSKY, G. O império do efêmero. A moda e seu destino nas sociedades modernas. São Paulo: Companhia das Letras, 1987.

LUKES, S. Power. Readings in social and political theory. Oxford: Basil Blackwell, 1986.

MIGUELES, C. 0 exercício do poder pelos administradores e a motivação dos empregados: algumas considerações teóricas sobre esta relação. Revista de Administração Pública - RAP, Rio de janeiro, v.33, n.3, p.113-138, maio/jun. 1999. 
Trabalho, poder e subjetividade na gestão empreendedora. Revista Portuguesa e Brasileira de Gestão, Rio de Janeiro; Lisboa, v.2, n.2, abril/jun. 2003. Disponível em: <www.indeg.or/rpbg>; <www.ebape.fgv.br/pesquisase publicacoes/rpbg>.

PRATES, M. A.; BARROS, T. 0 estilo brasileiro de administrar: sumário de um modelo de ação cultural brasileiro com base na gestão empresarial. In: MOTTA, F.; CALDAS, M. Cultura organizacional e cultura brasileira. São Paulo: Altas, 1997.

RICHARSON, R. Pesquisa social: métodos e técnicas. São Paulo: Atlas, 1999.

ROCHE, W.; MacKinnon, N. M otivating people with meaningful work. Harvard Business Review. Reprints of selected articles on motivation, Harvard College, 1970 (original article on HBR, n.70308, May/J une 1970).

SAHLINS, M. Culture and practical reason. Chicago: The University of Chicago Press, 1976.

SCHEIN, E. Organizational culture and leadership. San Francisco: Jossey- Bass Publishers, 1992.

SERVA, M. A Importação de metodologias administrativas no Brasil - uma análise semiológica. Revista de Administração Pública - RAP, Rio de Janeiro, v.26, n.4, p.128-144, out./dez. 1992.

SLATER, D. Consumer culture $\&$ modernity. Cambridge: Polity Press, 1997.

; TONKISS, F. Market society. Cambridge: Polity Press, 2001.

WEBER, M. Economia e sociedade. Braślia: Editora da UnB, 2000. 